\title{
Imperfect antitrust enforcement
}

Citation for published version (APA):

Schinkel, M. P., \& Tuinstra, J. (2002). Imperfect antitrust enforcement. METEOR, Maastricht University School of Business and Economics. METEOR Research Memorandum No. 031

https://doi.org/10.26481/umamet.2002031

Document status and date:

Published: 01/01/2002

DOI:

10.26481/umamet.2002031

Document Version:

Publisher's PDF, also known as Version of record

\section{Please check the document version of this publication:}

- A submitted manuscript is the version of the article upon submission and before peer-review. There can be important differences between the submitted version and the official published version of record.

People interested in the research are advised to contact the author for the final version of the publication, or visit the DOI to the publisher's website.

- The final author version and the galley proof are versions of the publication after peer review.

- The final published version features the final layout of the paper including the volume, issue and page numbers.

Link to publication

\footnotetext{
General rights rights.

- You may freely distribute the URL identifying the publication in the public portal. please follow below link for the End User Agreement:

www.umlib.nl/taverne-license

Take down policy

If you believe that this document breaches copyright please contact us at:

repository@maastrichtuniversity.nl

providing details and we will investigate your claim.
}

Copyright and moral rights for the publications made accessible in the public portal are retained by the authors and/or other copyright owners and it is a condition of accessing publications that users recognise and abide by the legal requirements associated with these

- Users may download and print one copy of any publication from the public portal for the purpose of private study or research.

- You may not further distribute the material or use it for any profit-making activity or commercial gain

If the publication is distributed under the terms of Article $25 \mathrm{fa}$ of the Dutch Copyright Act, indicated by the "Taverne" license above, 


\title{
Imperfect Antitrust Enforcement*
}

\author{
Maarten Pieter Schinkel ${ }^{\dagger}$ and Jan Tuinstra ${ }^{\ddagger}$
}

November 18, 2002

\begin{abstract}
Competition policy is a subject of heated debate. Antitrust authorities, seeking to battle anticompetitive behavior in complex cases to the best of their abilities, often find themselves advised by rival economic theories and disputed empirical analyses. As a consequence, there is a real possibility that authorities may occasionally err, missing true violations of competition law or finding firms liable that have indeed done nothing but good competition. In this paper, some consequences of such imperfect antitrust enforcement on firms' strategies are considered. It is found that the incidence of anti-competitive behavior increases in the enforcement error. This is due to a decrease in expected fines, but particularly also to industries colluding precautionary when they face the risk of false allegations. Moreover, the larger the enforcement error, the more likely it is that authorities are over-zealous - in the sense that welfare is better served by an antitrust authority that is lenient.
\end{abstract}

Keywords: Antitrust enforcement, imperfect information, competition policy. JEL-codes: L40, D40.

\section{Introduction}

Competition policy is controversial and typically advised by rival economic theories. It is easy to find contributors to the central debate whether antitrust intervention is a cure for imperfect competition and inefficiency or rather a cause, that take the latter

\footnotetext{
* We have benefited from appreciated suggestions for improvements to an earlier draft by Peter van Bergeijk, Franklin Fisher and Sander Onderstal.

$\dagger$ Department of Economics, Universiteit Maastricht, P.O. box 616, 6200 MD Maastricht, The Netherlands. E-mail: m.schinkel@algec.unimaas.nl. Corresponding author.

¥ Department of Quantitative Economics and CeNDEF, Universiteit van Amsterdam, Roeterstraat 11, 1018 WB Amsterdam, The Netherlands. E-mail: tuinstra@fee.uva.nl. This research was conducted while visiting Universiteit Maastricht. Financial support from METEOR is gratefully acknowledged.
} 
view without reserve. ${ }^{1}$ Exponents of the so-called "Chicago-view," such as Robert Bork and Richard Posner, point to a variety of reasons why one should be wary of antitrust. ${ }^{2}$ They stress that it is often difficult to determine whether allegations of anticompetitive behavior indeed have merit, or whether the conduct found is, in fact, rather a sign of good competition. Moreover, they express concern for the appropriateness of the enforcement process, knowing from first hand experience that antitrust cases are complicated and costly, yet often handled by "[t]rial lawyers [that] tend to be combative rather than reflective, and ... division's trial lawyers [that], because they are relatively poorly paid, tend to be young or mediocre, or to be zealots," who,

"[a]s a result of neglect of economic principles, ... have fashioned a body of substantive doctrine and a system of sanctions and procedures that are poorly suited to carrying out the fundamental objectives of antitrust policy - the promotion of competition and efficiency." (Posner, 1976, pp. $231-6)^{3}$

Baumol and Ordover (1985) raises the issue of antitrust institutions being misused as an instrument of monopolization, rather than working against it. The authorities may be seduced to bring spurious antitrust cases, intended to subvert competition-a "specter," they say, that is likely to be "...more than offsetting the contributions to economic efficiency promised by antitrust activities," and that we "would do well to take steps to exorcise." 4

The wording that these authors choose is rather strong, yet a reserve towards antitrust intervention is found with scholars that are sympathetic to checking competitive processes, as well. Franklin Fisher, an antitrust veteran in both defendant and plaintiff camps, for example, teaches on the difficulty to establish true anticompetitive behavior that:

"Economists and others ought to approach the public policy problems involved in these areas with a certain humility. Real industries tend to be very complicated. One ought not to tinker with a well-performing industry on the basis of simplistic judgments. The diagnosis of the monopoly disease is sufficiently difficult that one ought not to proceed to surgery without thorough examination of the patient and a thorough understanding of the medical principles involved." (Fisher, 1991, p.32)

\footnotetext{
1 See on this the remarkable theater-of-the-absurd courtroom dialogue in Adams and Brock (1991).

2 Cf. Bork (1993) and Posner (1976, 2002).

3 In the recent and extentively re-edited 2002 edition of this book, Posner expresses similar concern, albeit in somewhat milder terms.

4 Op.cit., p.247.
} 
And Stephen Martin, an evident advocate of the so-called "Harvard-view," acknowledges problems with antitrust enforcement too in the closing chapter of his introductory textbook into the economics of competition policy. ${ }^{5}$

Controversy has, consequently, surrounded antitrust practice from the very formulation of the Sherman Act. Bork (1966) narrates how several senators asked that men of "superior skill and intelligence," that thus obtained dominance in their markets, were to be kept from being made "culprits by the bill." Early conflicting Supreme Court decisions in the Standard Oil case in 1911 and U.S. vs. United States Steel in 1920, where in the latter case the court passed overt and clear collusion by majority vote, paralyzed the Sherman Act until after World War II. Likewise, in one of the first major European Commission convictions based on the Treaty of Rome, Continental Can in 1973, the European Court of Justice found on appeal in favor of the defendant. And U.S. vs. Microsoft Corp. pivoted around the question whether Microsoft bundled Internet Explorer with Windows to produce a competitive product necessary to survive in the operating systems market, or whether instead it did so out of predatory motives.

With so much indication that the enforcement of competition policy may not be trouble free, the question presents itself as to what could be the consequences of antitrust cases brought that in hindsight turned out to have had little merit, or worse, that led to false convictions. Again, conjectures are quite strong. Harold Demsetz, for example, held that errors are made in about one half of US cases:

"Unfortunately, our antitrust laws are being used to protect competitors and penalize efficiency. Competitive pricing policies, effective advertizing campaigns, and the efficient management of resources are as likely to run afoul of antitrust as are attempts to collude." (Demsetz, 1974, p.183, italics added)

It is however difficult, if not impossible, to obtain statistics of mistaken antitrust convictions. Indicative may nevertheless be a recent empirical survey of US Department of Justice antitrust enforcement by Gallo et.al., summarizing data from the Commerce Clearing House Bluebook. ${ }^{6}$ The study has a section on the won-loss record of the department. From 1955 through 1997, the DOJ won 86 percent of all individual cases, which the authors celebrate. The definition of a win, however, is taken conveniently broadly: a case counts as a win when at least one defendant is convicted and includes plea arrangements, consent decrees, no contest, nolo contendere and injunctions to prevent merger, for which there is often reason even for innocent firms to engage in. Moreover, the average is increased by successful criminal cases: 92 percent won, versus 77 percent civil cases, which is attributed to greater investigatory efforts channeled to criminal cases, as well as the fact that these are "hard-core per

\footnotetext{
5 Martin (1993), Chapter 18.

6 Gallo, et.al. (2000), pp.112-119.
} 
se violations" of which "the illegality of the practice is clear," and that dealt almost exclusively with small firms, without the means to obtain good legal advice. ${ }^{7}$ Even when one looks at it quite sympathetically, therefore, still a good one fifth of US violations alleged by the people turned out false.

Similar studies on European Commission cases are, to our knowledge, not available. One reason for this may be that comparable EU statistics are harder to obtain, due to the more introvert enforcement culture Europe has - for example leading to many settlement clearances. Some tentative results on cases taken up by the Monopolies and Merger Commission in the United Kingdom reported in Davies et.al. (1999), and a recent study on the "success rate" of the German Bundeskartelamt in Lauk (2002), however, suggest that in roughly one third of the U.K. cases, to one quarter of German antitrust investigations the charges against alleged violators were eventually dropped. Again, also, the more complicated cases, such as vertical restraints other than exclusive dealing - which is the most clear cut - are found to be least likely to result in an adverse finding. There is no reason to think that at least EU member practice is any less fallible, therefore.

The principal problem in formulating antitrust policy that makes its enforcement open to mistakes is the lack of information possessed by the authority on relevant data such as firm costs, consumer demand, prices, sales and possible collusive agreements. In a distinct literature on antitrust enforcement, in which Besanko and Spulber (1989) is the central reference, the consequences of such asymmetric information are studied. Industries can be of different, a priori for the antitrust authority unknown cost types, so that observed production levels can be a sign of collusive behavior with low costs, as well as competition with high costs. When antitrust investigation is costly, the general finding is that welfare is maximized when modest levels of collusion in low-cost industries are tolerated, whereas the authority commits itself to investigate firms that (in equilibrium) produce competitive quantities in the high cost industry with positive probability, both to prevent them from cartelizing and to moderate the collusive behavior in the low-cost industry. ${ }^{8}$

Although this literature introduces the probability of investigation and suit, however, it assumes that once firms have been targeted for inspection, the antitrust authority is able to determine with certainty whether or not the law has been violated. That is, in Besanko and Spulber (1989), the antitrust authority can err by suing

\footnotetext{
7 Op.cit., p.119.

8 The Besanko-Spulber model relates to a literature on a principal-agent approach to tax compliance, in which comparable optimal enforcement results are obtained - $c f$. Reinganum and Wilde (1985). There are some results on the consequences of errors in tax auditing, relating them to the complexity of tax laws and the training of auditors and courts - cf. Scotchmer and Slemrod (1989) and Kaplow and Shavell (1994). Interestingly enough, it is found that randomness typically edges tax payers to compliance and allows audit expenses to be directed better, increasing total tax revenue - cf. Andreoni, Erard and Feinstein (1998). Extensions on Besanko and Spulber (1989) include Cyrenne (1999) and Souam (2001), which have taken up issues of commitment and different fine structures.
} 
firms that are subsequently found to have acted competitively, or by deciding not to prosecute firms that are, in fact, colluding, but screening always lifts the asymmetric information problem fully. ${ }^{9}$ When it is assumed that investigatory procedures do not necessarily reveal the truth about parties' behaviors, however, two different kinds of deviations from the null hypothesis that only firms that indeed acted anticompetitively are successfully prosecuted arise: Type I errors - finding an industry that is competitive liable of anticompetitive behavior - and Type II errors - acquitting companies that have in fact acted anticompetitively.

In this paper, fallible, and therefore imperfect antitrust enforcement is introduced in a model in which firms can be of three different cost types. To simplify matters, the analysis is restricted, without loss of generality, to a discrete action space, where industries choose from a set of three different outputs, the competitive levels corresponding to the three costs types. Low-cost type firms producing high-cost type outputs are able to do so by means of collusion and make a profit. By the same logic, a firm that produces the low cost competitive output, is of low cost type with certainty. Type I and Type II errors can occur, therefore, at lower output levels.

It is found that the incidence of anti-competitive behavior increases in the antitrust authority's enforcement error, for two reasons. The first, and most obvious, reason is that the probability of getting caught when behaving anticompetitively goes down, leading to lower expected fines for firms investigated. The second reason is that the risk of being fined despite behaving competitively goes up, inducing industries to collude as a 'precautionary' measure. These two unambiguous effects lead up to the conclusion that the larger the enforcement error, the more likely it is that authorities are over-zealous - in the sense that welfare is better served by an antitrust authority that is lenient. Some numerical examples illustrate these findings.

The paper is organized as follows. The next section presents the model. Section 3 studies the benchmark situation, in which the antitrust authority has the ability to determine with certainty the type of industry upon investigation. In Section 4 this assumption is dropped and the consequences of imperfect antitrust enforcement are studied. Section 5 concludes with some refinement of the results, referring to current developments in European antitrust practice, involving more economic argument in litigation, as in the US.

\section{The Model}

Consider an economy with industries that each consist of an equal number of identical risk-neutral firms producing a homogeneous product for which consumer demand is given by a nonincreasing inverse demand function $P(q)$, where $q$ is industry output.

9 In the typical partially competitive equilibrium that Besanko and Spulber (1989) bring to the fore as generally socially optimal, the first type of error prevails as only innocent firms are sued, and after costly trial found not to be liable and, therefore, acquitted. This is clearly not in accordance with the statistics reported on in the text above, supporting our preposition that antitrust is fallible. 
Each industry is characterized by the constant marginal cost level $\theta$ of the firms operating in it, which can take on three different values, $\theta_{3}>\theta_{2}>\theta_{1} \geq 0$. The actual cost-type is known to the firms in the industry, but not to the authority, which assigns probability $\gamma_{i}$ to the event that the industry is of cost-type $i$-naturally, $\gamma_{1}+\gamma_{2}+\gamma_{3}=1$

Given their cost structure, firms in an industry have the option to behave competitively, or to collude and reduce output. If they behave competitively, firms produce at marginal costs in Bertrand-Nash equilibrium, so that industry output $q_{i}, i=1,2,3$ is on the perfectly competitive level, implicitly defined by $P\left(q_{i}\right)=\theta_{i}$. Industry profits, defined as

$$
\pi\left(q, \theta_{i}\right) \equiv P(q) q-\theta_{i} q
$$

are then equal to zero. Note that by construction $q_{1}>q_{2}>q_{3}$.

If an industry colludes, it conspires to produce less than the competitive output. In order to hide its anti-competitive arrangements from the authorities, the cartel picks the competitive output of another industry type. ${ }^{10}$ That is, a collusive industry of type $i$ earns industry profits $\pi\left(q_{j}, \theta_{i}\right)>0$ with $j>i{ }^{11}$ Note that this setup implies that there is no possibility for type 3 industries to collude.

In the absence of antitrust intervention, industry payoffs are represented in Table 1 , where the ' $\times$-s' in the upper-right cells follow from the assumption that an industry will never produce more than its competitive output.

\begin{tabular}{l|lll} 
& $\theta_{1}$ & $\theta_{2}$ & $\theta_{3}$ \\
\hline$q_{1}$ & 0 & $\times$ & $\times$ \\
$q_{2}$ & $\pi\left(q_{2}, \theta_{1}\right)$ & 0 & $\times$ \\
$q_{3}$ & $\pi\left(q_{3}, \theta_{1}\right)$ & $\pi\left(q_{3}, \theta_{2}\right)$ & 0
\end{tabular}

Table 1: Industry pay-off matrix without antitrust intervention.

Without the threat of antitrust intervention, a type 1 industry will produce $q_{2}$ or $q_{3}$-whichever gives it the highest profit - and a type 2 industry will produce $q_{3}$. Type 3 industries always behave competitively at zero profits. Also note that the labelling of marginal costs implies that $\pi\left(q_{3}, \theta_{1}\right)>\pi\left(q_{3}, \theta_{2}\right)$.

Typically, the collusive behavior of type 1 and type 2 industries runs the risk of being policed by the antitrust authority. As demand is common knowledge, the

\footnotetext{
10 Here, the present model deviates from Besanko and Spulber (1989), in which firms can pick any real-valued quantity lower than $q_{i}$. Since it is not that much the level of collusion, as the qualitative effects of antitrust errors, that is central in the present analysis, this setup suffices. Keeping to the Besanko-Spulber setup would complicate the present analysis without adding to the key insights. Moreover, the present model allows for a full characterization of the spectrum of socially optimal antitrust regimes.

11 As is customary in this literature, issues of cartel stability are neglected. A collusive industry is assumed to be able to sustain profits.
} 
authority can observe the industry price and output perfectly. Without costly investigation, however, it has no information about cost types. Consequently, when the authority observes an output of $q_{2}$, it cannot distinguish between a competitive industry of type 2 or a collusive industry of type 1 . Likewise, when $q_{3}$ is produced, the authority cannot a priori tell a competitive type 3 industry from either a type 1 or a type 2 industry colluding.

In order to fight collusive behavior, the antitrust authority commits to an investigation policy $\left(\beta_{2}, \beta_{3}\right) \in[0,1] \times[0,1]$, where $\beta_{i}$ is the probability with which the authority investigates an industry when it sees an output level of $q_{i}$, for $i=2,3$. $^{12}$ Obviously, there is no reason for the antitrust authority to investigate an industry producing $q_{1}$, since this output level can only profitably be the competitive output of a type 1 industry.

Suppose, as the literature on imperfect antitrust enforcement does, that if the antitrust authority decides to investigate an industry, it learns the industry's type with certainty. Should it find collusive behavior, the industry is found liable of anticompetitive behavior and levied a fine of size $A$. It is assumed that $A$ is larger than the profit any industry can maximally obtain by colluding - as otherwise industries will always collude. Note that, since imposing fines is assumed to be costless for the antitrust authority whereas investigation is not, fine levels should in fact be set as large as possible. ${ }^{13}$ However, in practice fines are bounded. In fact, in public US cases, it is injunctions rather than fines that are used to correct anti-competitive acts. Moreover, in private cases, remedies are related to damages incurred by the sueing party. In Europe, fines often are more substantial, yet arguments to punish 'reasonably' apply. Therefore, fines, when levied at all, are typically of the type used in the present model - as well as relatively small compared to investigation costs or profits. ${ }^{14}$

The authority's policy $\left\{\left(\beta_{2}, \beta_{3}\right), A\right\}$ results in expected payoffs for the industries displayed in Table 2.

Each time the antitrust authority decides to investigate an industry, it pays investigation costs $K$. It is the authority's objective to maximize total welfare, defined

12 Note that any uncertainty on the side of firms as to the probability with which they will be visited by the antitrust authority — one possible dimension of antitrust enforcement - would lead to firms perceiving a distribution over various values of $\beta$, which reduces to a point estimate. At best, this would drive a wedge between the objective probability of suit, and the firms' subjective evaluation of it. Such a diferrence would converge over time by observing the authority's behavior, however.

13 This is in keeping with the seminal argument in Becker (1968).

14 Cf. Besanko and Spulber (1989), p.410 and Section VII (A), pp.420-1. A more complete theory would introduce welfare costs of large fines - typically relying on the argument that wrongful fining, which we introduce, is socially undesirable-leading to an optimal fine level. Also, we can make fines dependent upon the output level-so that there are three fine levels, $A_{i}, i=1,2,3$ and obtain qualitatively identical results. Should fines be allowed to be very large, particularly in comparison to the investigation costs $K$, then our results would largely vanish — see also Section 5 , Concluding Remarks. 


\begin{tabular}{l|llc} 
& $\theta_{1}$ & $\theta_{2}$ & $\theta_{3}$ \\
\hline$q_{1}$ & 0 & $\times$ & $\times$ \\
$q_{2}$ & $\pi\left(q_{2}, \theta_{1}\right)-\beta_{2} A$ & 0 & $\times$ \\
$q_{3}$ & $\pi\left(q_{3}, \theta_{1}\right)-\beta_{3} A$ & $\pi\left(q_{3}, \theta_{2}\right)-\beta_{3} A$ & 0
\end{tabular}

Table 2: Industry pay-off matrix with perfect antitrust investigation.

as the expected sum of consumer and producer surplus minus expected total investigation costs. That is, total welfare for a certain output $\left(q_{i}, q_{j}, q_{3}\right)$, where $q_{i}$ is the output of the type 1 industry and $q_{j}$ is the output of the type 2 industry, $i \in\{1,2,3\}$ and $j \in\{2,3\}$, is given by

$$
\begin{aligned}
W\left(q_{i}, q_{j}, q_{3}\right)= & \gamma_{1}\left(V\left(q_{i}\right)-\theta_{1} q_{i}-\beta_{i} K\right)+\gamma_{2}\left(V\left(q_{j}\right)-\theta_{2} q_{j}-\beta_{j} K\right) \\
& +\gamma_{3}\left(V\left(q_{3}\right)-\theta_{3} q_{3}-\beta_{3} K\right),
\end{aligned}
$$

in which

$$
V\left(q_{i}\right)-\theta_{i} q_{i} \equiv \int_{0}^{q_{i}} P(y) d y-\theta_{i} q_{i}
$$

is the sum of consumer and producer surplus. Note that $V(q)-\theta_{i} q$ is increasing in $q$ for $q<q_{i}$. Furthermore, observe that the fines imposed on an industry do not appear in the welfare function. This is not due to their 'lump-sum' nature, as one might think. Fines do affect the behavior of firms - as they are designed to do. They enter, however, as a welfare-neutral redistribution of income, given the level of output. The optimal antitrust enforcement regime maximizes (1), given the incentive constraints for the industries set out in the sections below. ${ }^{15}$

It is the objective of the present analysis to understand the effects of Type I and Type II errors in enforcement. Let $\widehat{\theta}$ be the antitrust authority's conclusion on the type of industry it faces after investigation. Then, $\alpha_{i j}\left(q_{k}\right)$ is the probability that, upon observing $q_{k}$, the antitrust authority concludes $\widehat{\theta}=\theta_{j}$ when the true cost is $\theta_{i} \cdot{ }^{16}$ In other words,

$$
\alpha_{i j}\left(q_{k}\right) \equiv \operatorname{Pr}\left(\widehat{\theta}=\theta_{j} \mid \theta_{i}, q_{k}\right) \text { for } i, j, k=1,2,3 .
$$

Naturally, for each $i$ and $k$, the authority has a complete conjecture of the types.

\footnotetext{
15 Note that the antitrust authority faces no budget constraint-again, following Besanko and Spulber (1989). If it would, the overall conclusion of the present analysis that antitrust enforcement is best selective and careful would typically be fortified-see Concluding Remarks.

16 Note that the probability of bringing antitrust cases that indeed have no merit is typically a (decreasing) function of the investigation effort per case, $K$, of the authority. Since these are assumed to be constant here, however, the probabilities $\alpha_{i j}\left(q_{k}\right)$ are exogenously given in this model-for more on this, see Concluding Remarks.
} 
That is,

$$
\sum_{j=1}^{3} \alpha_{i j}\left(q_{k}\right)=1
$$

Several things are obvious about the possible errors. By the construction of the possible industry structures, the matrix of probabilities is importantly reduced. When $q_{1}$ is observed, $\alpha_{12}\left(q_{1}\right)=\alpha_{13}\left(q_{1}\right)=0$ so $\alpha_{11}\left(q_{1}\right)=1$. Likewise, when $q_{2}$ is observed, $\alpha_{13}\left(q_{2}\right)=\alpha_{23}\left(q_{2}\right)=0$. The following assumption further limits the notational burden.

Assumption 1 (i) The probability of error is symmetric, that is

$$
\alpha_{i j}\left(q_{k}\right)=\alpha_{j i}\left(q_{k}\right) \text { for } i, j=1,2,3 \text { and } k=2,3 \text {. }
$$

(ii) The probability of error is constant, and indicated as $\alpha$, that is

$$
\alpha_{13}\left(q_{3}\right)=\alpha_{23}\left(q_{3}\right)=\alpha_{12}\left(q_{2}\right) \equiv \alpha
$$

The symmetry assumption is mildly restrictive. Typically, there is no particular reason to assume that the antitrust authority would be able to distinguish between symmetric cases. Part (ii) of Assumption 2 is less innocent, yet defendable. It implies that the antitrust authority is more likely to make judgment errors, the more different possible market structures can underlie the observed quantities. Alternatively put, the more cost types are excluded by the industry's revealed behavior, the smaller is the error made by the antitrust authority. Assuming the probability of error to be constant seems more appropriate than its simple counterpart, that is, keeping the total probability of error constant, irrespective of the complexity of the industry under investigation. A more satisfactory setup allows for different probabilities for each possible type of error, with general conditions on their relationships. This complicates the notation greatly, without adding substantially to the strength of the points here made.

Note that Assumption 2 has implications for the probability with which Type I errors (finding an innocent firm liable) and Type II errors (passing a liable firm) are made. When $q_{2}$ is observed, the symmetry assumption on $\alpha$ implies symmetry in the error types - each of size $\alpha$. When $q_{3}$ is observed, however, it no longer does. Since an industry can be prosecuted and fined for anti-competitive acts that it indeed commited, yet on the basis of a cost structure conjectured falsely by the authority, the consequences of the judgment error when $q_{3}$ is observed are less consequential, since the fining as such is appropriate. Formally,

$$
\begin{gathered}
\operatorname{Pr}\left(\text { Type I } \mid q_{3}\right)=\operatorname{Pr}\left(\widehat{\theta} \neq \theta_{3} \mid \theta_{3}, q_{3}\right)=\operatorname{Pr}\left(\widehat{\theta}=\theta_{1} \mid \theta_{3}, q_{3}\right)+\operatorname{Pr}\left(\widehat{\theta}=\theta_{2} \mid \theta_{3}, q_{3}\right)=2 \alpha, \\
\operatorname{Pr}\left(\text { Type II } \mid q_{3}\right)=\operatorname{Pr}\left(\widehat{\theta}=\theta_{3} \mid \theta_{1}, q_{3}\right)=\operatorname{Pr}\left(\widehat{\theta}=\theta_{3} \mid \theta_{2}, q_{3}\right)=\alpha,
\end{gathered}
$$


where the latter is true since when $\widehat{\theta}=\theta_{2}$ there is (correctly) a fine levied as well. Hence, the simplifying assumptions introduce an asymmetry in the error distribution. This distribution over error types may be criticized for rather being reversed in the actual antitrust practice. In doing so, however, note that Type I errors pertain to the industries that are indeed investigated, not the ones that were never visited in the first place - in practice most likely the bulk of missed violations. ${ }^{17}$

The full impact of the antitrust authority's policy $\left\{\left(\beta_{2}, \beta_{3}\right), A\right\}$, including the possibility that a liable industry under investigation escapes correction, and an innocent industry may be wrongfully fined, results in a modification of the expected industry payoff table, given in Table 3.

\begin{tabular}{l|lll} 
& $\theta_{1}$ & $\theta_{2}$ & $\theta_{3}$ \\
\hline$q_{1}$ & 0 & $\times$ & $\times$ \\
$q_{2}$ & $\pi\left(q_{2}, \theta_{1}\right)-\beta_{2}(1-\alpha) A$ & $-\beta_{2} \alpha A$ & $\times$ \\
$q_{3}$ & $\pi\left(q_{3}, \theta_{1}\right)-\beta_{3}(1-\alpha) A$ & $\pi\left(q_{3}, \theta_{2}\right)-\beta_{3}(1-\alpha) A$ & $-2 \beta_{3} \alpha A$
\end{tabular}

Table 3: Industry pay-off matrix with imperfect antitrust intervention.

Figure 1 illustrates the various decisions as sequential moves in an extensive form game. For simplicity, the figure has been reduced to display only those choices that can possibly be made - that is, those type-quantity matches that will not occur because it is never profitable to produce more than the competitive output that goes with one's type are not drawn in.

First, nature $(N)$ decides on the cost structure of the industry. Then, the industry $(I)$ decides whether or not to collude, after which suit is brought or not, with a probability committed to by the antitrust authority $(A)$, and depending on the observed quantity - note that each is an information set. When quantity $q_{2}$ is observed, and in case of an investigation, with probability $\alpha$ the firm is falsely assessed. When $q_{3}$ is observed, the antitrust authority can err twice, taking the industry for a type 2 or a type 3 , where it is type 1 , for a type 1 or a type 3 , where it is a type 2 , or for a type 1 or 2 , when it is a type 3 . This results in the three-way splits associated with investigation upon observing $q_{3}$.

It is important to note that any false judgments on the part of the antitrust authority has no influence on the welfare function (1), since misallocated fines amount to a random redistribution of income - again, this is not due to the lump-sum structure of the fines. The incentive constraints of the firms, however, are importantly affected.

\footnotetext{
17 Note that the present analysis could be extended to one with an explicit asymmetric distribution over Type I and Type II errors that can be an object of policy. An obvious way to do this it to introduce that when a firm is found liable, a second investigation round is entered, with associated costs and room for errors - whereas a firm that is found not-liable in the first round is left alone. Such an appeals system allows for the type of socially desirable fine level referred to in footnote 14 , by weighing the consequences of Type I and Type II errors.
} 


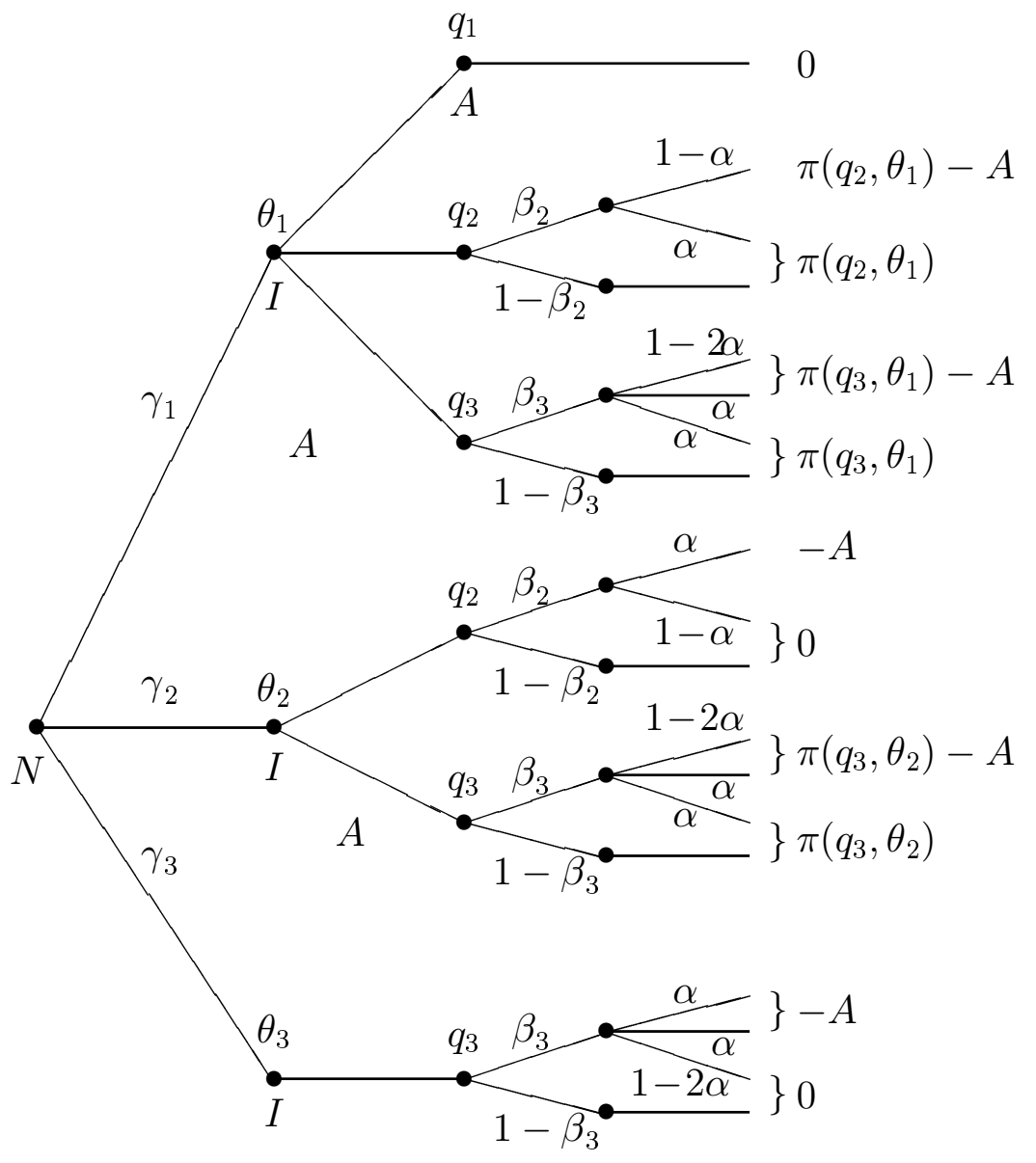

Figure 1: The sequence of moves by nature, industry and authority.

In the remainder of this paper, we study the effects of this in detail, determining when they apply and what their welfare consequences are. To that end, the next section reviews the model when the antitrust authority is infallibly able to identify industries - that is, we regress to the discrete version of the Besanko-Spulber model for comparison, only to return to the full model in Section 4.

One final restriction of the variety of effects in our model is in order here. To prevent it from being attractive for type 1 industries to attempt to collude at the $q_{3}$ level, we assume that a larger profit can be obtained from producing $q_{2}$. That is, we make the following assumption.

Assumption $2 \pi\left(q_{2}, \theta_{1}\right)>\pi\left(q_{3}, \theta_{1}\right)$.

Note that this being known to the antitrust authority has no effect on the probabilities of mistakes. The reverse case, in which the type 1 industry is inclined to collude on the competitive output of the type 3 industry generates qualitatively similar, albeit socially inferior, results. 


\section{Antitrust with Perfect Monitoring}

Consider the incentive constraints for the different types of industries when the antitrust authority can perfectly observe the type upon investigation. Making the common assumption that when an industry is indifferent between two output levels it chooses the one most preferred by the antitrust authority - that is, the highest production level - the incentive constraints of the industry are as follows. A type 1 industry produces the competitive output $q_{1}$ only if it expects a loss from colluding, that is if

$$
\pi\left(q_{2}, \theta_{1}\right)-\beta_{2} A \leq 0 \text { and } \pi\left(q_{3}, \theta_{1}\right)-\beta_{3} A \leq 0,
$$

as it makes zero profits in perfect competition. It will produce $q_{2}$ if such is better than competing at $q_{1}$ and colluding at $q_{3}$, that is if

$$
\pi\left(q_{2}, \theta_{1}\right)-\beta_{2} A \geq \pi\left(q_{3}, \theta_{1}\right)-\beta_{3} A \text { and } \pi\left(q_{2}, \theta_{1}\right)-\beta_{2} A>0 .
$$

Finally, a type 1 industry will opt for $q_{3}$ if

$$
\pi\left(q_{3}, \theta_{1}\right)-\beta_{3} A>\pi\left(q_{2}, \theta_{1}\right)-\beta_{2} A \text { and } \pi\left(q_{3}, \theta_{1}\right)-\beta_{3} A>0 .
$$

For type 2 industries, there are only two choices. Either it produces $q_{2}$ if

$$
\pi\left(q_{3}, \theta_{2}\right)-\beta_{3} A \leq 0
$$

or $q_{3}$ otherwise. By construction, type 3 industries will always produce $q_{3}$.

As type 1 industries can choose three output levels, type 2 industries two, and type 3 industries only one, there is a total of six different outputs that could potentially be observed. It is not difficult to show, however - see the appendix for the proof of this result, and the ones to follow - that only three of these can be welfare maximizing. That is, the antitrust authority will decide on its enforcement policy, seeking to implement one of only three market structures. ${ }^{18}$

Proposition 1 When antitrust enforcement is perfect, the antitrust authority seeks to implement one of the following three market structures:

1. perfect competition, with outputs $\left(q_{1}, q_{2}, q_{3}\right)$, that is, every industry type chooses the competitive output;

2. partial collusion, with outputs $\left(q_{2}, q_{2}, q_{3}\right)$, that is, only type 1 industries collude; or

3. full collusion, with outputs $\left(q_{2}, q_{3}, q_{3}\right)$, that is, type 1 and type 2 industries collude.

\footnotetext{
18 Proposition 1 in Besanko and Spulber (1989) likewise finds for their two-type model that the combination low-cost industry competitive output, high-cost industry collusive output never occurs (op.cit., p. 414.)
} 
The proposition says that the partially collusive output $\left(q_{1}, q_{1}, q_{3}\right)$ cannot be implemented. The reason for this is that deterring type 1 industries from producing $q_{3}$ also keeps type 2 industries from producing output level $q_{3}$. Likewise, outputs $\left(q_{3}, q_{2}, q_{3}\right)$ and $\left(q_{3}, q_{3}, q_{3}\right)$ can never be welfare maximizing, because both type 1 industries - by Assumption 2-and the antitrust authority prefer output levels $q_{2}$ to $q_{3}$.

Among the three policies open to the antitrust authority, it is to select the one with the highest welfare. Which one depends on the parameter constellation. Proposition 2 characterizes when each of the outputs is optimal, for variable values of the ratio between the investigation costs $K$ and the fine $A, \frac{K}{A}$.

Proposition 2 When antitrust enforcement is perfect, there exist well-defined positive numbers $\Psi_{a}, \Psi_{b}$ and $\Psi_{c}$, with either i) $\Psi_{a} \leq \Psi_{b} \leq \Psi_{c}$ or ii) $\Psi_{c} \leq \Psi_{b} \leq \Psi_{a}$, such that:

1. If ordering i) holds:

perfect competition, with outputs $\left(q_{1}, q_{2}, q_{3}\right)$, is optimal for $\frac{K}{A} \in\left[0, \Psi_{a}\right]$;

partial collusion, with outputs $\left(q_{2}, q_{2}, q_{3}\right)$, is optimal for $\frac{K}{A} \in\left[\Psi_{a}, \Psi_{c}\right]$; and

full collusion, with outputs $\left(q_{2}, q_{3}, q_{3}\right)$, is optimal for $\frac{K}{A} \geq \Psi_{c}$.

2. If ordering ii) holds:

perfect competition is optimal for $\frac{K}{A} \leq \Psi_{b}$; and

full collusion is optimal for $\frac{K}{A} \geq \Psi_{b}$.

This result supports the conjecture that low investigation costs make it optimal to implement the perfectly competitive equilibrium, whereas high investigation costs may make the collusive output, in which no enforcement is required, optimal. The interpretation of the critical values, developed in the appendix, is straightforward. Consider, for example, $\Psi_{a}$, the critical value of $\frac{K}{A}$ for which the antitrust authority is just indifferent between perfect competition and partial collusion:

$$
\Psi_{a}=\frac{\gamma_{1}\left(\left[V\left(q_{1}\right)-\theta_{1} q_{1}\right]-\left[V\left(q_{2}\right)-\theta_{1} q_{2}\right]\right)}{\gamma_{2} \pi\left(q_{2}, \theta_{1}\right)+\gamma_{3}\left[\pi\left(q_{3}, \theta_{1}\right)-\pi\left(q_{3}, \theta_{2}\right)\right]}
$$

The numerator represents the expected increase in total surplus from deterring a type 1 industry from colluding. The denominator of $\Psi_{a}$ reflects the costs of deterring type 1 industries. Only when the return from doing so is sufficiently large, that is, it pays to incur the enforcement costs to install perfect competition.

Typically, when the probabilities of the different cost-types occurring are reasonably symmetric, the ordering of Proposition 2.1 applies. Note, however, that when $\gamma_{1}$ increases, so that $\gamma_{2}$ and/or $\gamma_{3}$ decrease, $\Psi_{a}$ increases. The more likely it is that the authority faces a low cost type, therefore, the larger the region in which it is optimal to enforce perfect competition at a given cost. Similarly, $\Psi_{c}$, found to be the ratio 
of the increase in surplus resulting from keeping firm 2 from colluding and the costs thereof,

$$
\Psi_{c}=\frac{\gamma_{2}\left(\left[V\left(q_{2}\right)-\theta_{2} q_{2}\right]-\left[V\left(q_{3}\right)-\theta_{2} q_{3}\right]\right)}{\gamma_{3} \pi\left(q_{3}, \theta_{2}\right)},
$$

decreases when $\gamma_{2}$ decreases - possibly increasing $\gamma_{3}$. Hence, the less likely it is to confront a type 2 firm, and the more likely a firm is of type 3, with the more reserve the authority should intervene.

Finally, note that when the only other possible ordering of the regime boundaries, that of Proposition 2.2, holds, the partially collusive output cannot be welfare maximizing and the optimal regime changes from perfect competition to full collusion at $\Psi_{b}$.

An example may help to clarify the meaning of the different regimes found. Suppose inverse demand is linear and given as $P(q)=100-q$. Types are given as: $\theta_{1}=0$, $\theta_{2}=40$ and $\theta_{3}=80$. Consequently, $q_{1}=100, q_{2}=60$ and $q_{3}=20$. Profits corresponding to the collusive strategies are as follows.

$$
\pi\left(q_{2}, \theta_{1}\right)=2400, \pi\left(q_{3}, \theta_{1}\right)=1600 \text { and } \pi\left(q_{3}, \theta_{2}\right)=800 .
$$

Surplus is given by $V\left(q_{i}\right)=\int_{0}^{q_{i}} P(y) d y=100 q_{i}-\frac{1}{2}\left(q_{i}\right)^{2}$, so that

$$
V\left(q_{1}\right)=5000, V\left(q_{2}\right)=4200 \text { and } V\left(q_{3}\right)=1800 .
$$

The threshold values that segregate the optimal antitrust regimes for this example are found to be the following.

$$
\Psi_{a}=\frac{\gamma_{1}}{3 \gamma_{2}+\gamma_{3}}, \Psi_{b}=\frac{\gamma_{1}+\gamma_{2}}{3 \gamma_{2}+2 \gamma_{3}} \text { and } \Psi_{c}=\frac{\gamma_{2}}{\gamma_{3}}
$$

Suppose that $\gamma_{1}=\gamma_{2}=\gamma_{3}=\frac{1}{3}$. Then, the perfectly competitive output $(100,60,20)$ is welfare maximizing for the antitrust authority when $\frac{K}{A} \leq \frac{1}{4}$, the partial collusion outputs $(60,60,20)$ for $\frac{1}{4} \leq \frac{K}{A} \leq 1$, and the fully collusive output for $K \geq A$. This corresponds to the ordering in Proposition 2.1. Alternatively, the ordering of Proposition 2.2 applies in this example, for example, when $\gamma_{1}=\frac{1}{3}$ and $\gamma_{2} \leq \frac{1}{6}$. Then, full collusion can be socially preferred over perfect competition already when investigation costs are only more than a quarter of fines - that is, when $\gamma_{2}=0$.

\section{Imperfect Antitrust}

When the antitrust authority observes the industry type imperfectly and investigation is fallible, industry payoff Table 3 in Section 2 applies. The associated incentive constraints (2)-(5) are as follows. Type 1 firms choose to produce:

$$
\begin{aligned}
& q_{1} \text { if } \pi\left(q_{2}, \theta_{1}\right)-\beta_{2}(1-\alpha) A \leq 0 \text { and } \pi\left(q_{3}, \theta_{1}\right)-\beta_{3}(1-\alpha) A \leq 0 ; \\
& q_{2} \text { if } \pi\left(q_{2}, \theta_{1}\right)-\beta_{2}(1-\alpha) A \geq \max \left\{0, \pi\left(q_{3}, \theta_{1}\right)-\beta_{3}(1-\alpha) A\right\} \text { and; } \\
& q_{3} \text { if } \pi\left(q_{3}, \theta_{1}\right)-\beta_{3}(1-\alpha) A \geq \max \left\{0, \pi\left(q_{2}, \theta_{1}\right)-\beta_{2}(1-\alpha) A\right\} .
\end{aligned}
$$


Type 2 industries produce $q_{3}$ if

$$
\pi\left(q_{3}, \theta_{2}\right)-\beta_{3}(1-\alpha) A>-\beta_{2} \alpha A,
$$

and otherwise behaves competitively at $q_{2}$. Invariably, type 3 industries choose to produce $q_{3}$. Notice, however, that they do face possible penalties, now, when convicted innocently.

A first result compares the incentives of industries to collude with perfect and imperfect enforcement of competition law. When enforcement is imperfect, the incentive to collude goes up, for any given enforcement strategy, for two reasons. First, the probability of getting caught when behaving anticompetitively goes down, as can be seen by comparing the lower off-diagonal elements in Table 2 and Table 3 in Section 2. This decreases the expected costs of anticompetitive behavior. Second, and more interesting, innocent industries, because they run the risk of getting wrongfully fined when in fact behaving competitively, are induced to collude as a 'precautionary' measure.

More specifically, for a given antitrust policy $\left\{\left(\beta_{2}, \beta_{3}\right), A\right\}$, type 1 industries collude under imperfect antitrust enforcement, where they would not do so under perfect monitoring, if the cartel profit $\pi\left(q_{2}, \theta_{1}\right)$ satisfies

$$
\beta_{2}(1-\alpha) A<\pi\left(q_{2}, \theta_{1}\right)<\beta_{2} A
$$

in which only the expected-fines effect of enforcement errors plays a role. Type 2 industries, however, collude under imperfect monitoring and not under perfect monitoring if

$$
\beta_{3}(1-\alpha) A-\beta_{2} \alpha A<\pi\left(q_{3}, \theta_{2}\right)<\beta_{3} A,
$$

so that both effects of erroneous antitrust apply. The expected-fines effect, measured by $-\beta_{3} \alpha A$, provides an increased incentive to collude simply by lowering the probability of being caught. The precautionary-collusion effect, given by $-\beta_{2} \alpha A$, increases the incentive to collude through the positive probability of being fined unjustly.

The set of market structures that can be implemented and is possibly optimalthat is, the imperfect enforcement analogue of Proposition 1-is given below. Again, the proof is in the appendix.

Proposition 3 When antitrust enforcement is imperfect, the antitrust authority seeks to implement one of the following four market structures:

1. perfect competition, with outputs $\left(q_{1}, q_{2}, q_{3}\right)$, that is, every industry type chooses the competitive output;

2. type 1 partial collusion, with outputs $\left(q_{2}, q_{2}, q_{3}\right)$, that is, only type 1 industries collude; 
3. type 2 partial collusion, with outputs $\left(q_{1}, q_{3}, q_{3}\right)$, that is, only type 2 industries collude, which is feasible if

$$
\alpha \geq \alpha^{*} \equiv \frac{\pi\left(q_{3}, \theta_{1}\right)-\pi\left(q_{3}, \theta_{2}\right)}{A} ; \text { or }
$$

4. full collusion, with outputs $\left(q_{2}, q_{3}, q_{3}\right)$, that is, type 1 and type 2 industries collude.

This largest set of potentially optimal regimes is the same as that identified in Proposition 1, with one exception: since collusion is more difficult to fight for the reasons given above - not all offenders are caught, not even when monitored, and innocent firms run a risk of being wrongfully sued, giving them an incentive to collude - a first effect of imperfect monitoring is that a new optimal situation can occur, in which type 1 industries behave competitively, yet type 2 industries collude and conspire on the type 3 production level, provided the government error $\alpha$ is large enough.

In order to determine the conditions under which each of these different outputs is the welfare maximizing choice of government, the following. Consider a second critical value of $\alpha, \alpha^{* *}>\alpha^{*}$, defined as

$$
\alpha^{* *} \equiv \frac{\pi\left(q_{3}, \theta_{1}\right)-\pi\left(q_{3}, \theta_{2}\right)}{\pi\left(q_{2}, \theta_{1}\right)+\pi\left(q_{3}, \theta_{2}\right)-\pi\left(q_{3}, \theta_{1}\right)} .
$$

The expected-fines effect pertains to the situation with $\alpha \leq \alpha^{* *}$. In this case, a result analogous to Proposition 2 applies straightforwardly, with $\Psi_{i}, i=a, b, c$, replaced by $\Psi_{i}^{\alpha}=(1-\alpha) \Psi_{i}$. Clearly, such modest imperfection in antitrust increases the parameter region in which collusion is socially optimal. This is due to the fact that not all investigated and liable firms are fined, and the induction of competition therefore requires a higher risk of being investigated, hence more investigation costs, that are not offset by higher detection. The more subtle precautionary-collusion effect occurs for values of $\alpha$ higher than $\alpha^{* *}$. It leads to an even lower likelihood of the competitive output being optimal. Proposition 4 summarizes these results and establishes the relationship with Proposition 2.

Proposition 4 When antitrust enforcement is imperfect and type 2 partial collusion, with outputs $\left(q_{1}, q_{3}, q_{3}\right)$ is not optimal, there exist well-defined positive numbers $\Psi_{a}^{\alpha}$, $\Psi_{b}^{\alpha}$ and $\Psi_{c}^{\alpha}$ with either i) $\Psi_{a}^{\alpha} \leq \Psi_{b}^{\alpha} \leq \Psi_{c}^{\alpha}$ or ii) $\Psi_{c}^{\alpha} \leq \Psi_{b}^{\alpha} \leq \Psi_{a}^{\alpha}$, such that:

1. If ordering i) holds:

perfect competition, with outputs $\left(q_{1}, q_{2}, q_{3}\right)$, is optimal for $\frac{K}{A} \in\left[0, \Psi_{a}^{\alpha}\right]$;

type 1 partial collusion, with outputs $\left(q_{2}, q_{2}, q_{3}\right)$, is optimal for $\frac{K}{A} \in\left[\Psi_{a}^{\alpha}, \Psi_{c}^{\alpha}\right]$; and

full collusion, with outputs $\left(q_{2}, q_{3}, q_{3}\right)$, is optimal for $\frac{K}{A} \geq \Psi_{c}^{\alpha}$. 


\section{If ordering ii) holds:}

perfect competition is optimal for $\frac{K}{A} \leq \Psi_{b}^{\alpha}$; and

full collusion is optimal for $\frac{K}{A} \geq \Psi_{b}^{\alpha}$.

3. For $\alpha \leq \alpha^{* *}, \Psi_{i}^{\alpha}=(1-\alpha) \Psi_{i}, i=a, b, c$; and

for $\alpha>\alpha^{* *}, \Psi_{i}^{\alpha}<(1-\alpha) \Psi_{i}$ for $i=a$ or $b$,

where $\Psi_{a}, \Psi_{b}$ and $\Psi_{c}$ are defined in (the proof of) Proposition 2.

Note that the precautionary-collusion effect that further decreases $\Psi_{i}^{\alpha}$ below $(1-\alpha) \Psi_{i}$ only applies for the cases $a$ and $b$. That is, the transition from type 1 partial to full collusion as the socially optimally enforced regime is not affected by it. The reason for this is that in the type 1 partial collusive situation, the antitrust authority never investigates when it observes $q_{2}$. Therefore, neither type 1 firms colluding at $q_{2}$, nor type 2 firms competing at $q_{2}$ run the risk of being falsely convicted. Consequently, they have no incentive to collude as a precautionary measure. The precautionary-collusion effect only applies to the transition from perfect competition to partial collusion.

A second result that derives from imperfect antitrust enforcement is the novel possibility that the type 2 partially collusive equilibrium maximizes welfare. Crucial in this respect is the fraction of type 1 industries. If this fraction is high enough, it will pay for the antitrust authority to deter industries of this type from colluding, yet let type 2 industries go.

Proposition 5 Let $\alpha>\alpha^{*}$. Then, when antitrust is imperfect, there exists a welldefined number $\Gamma_{1}$ such that for $\gamma_{1}>\Gamma_{1}$ there is an interval of values of $\frac{K}{A}$ in which type 2 partial collusion, with outputs $\left(q_{1}, q_{3}, q_{3}\right)$, is optimal.

For the way $\Gamma_{1}$ derives, as well as for the borders of the interval in which the effect applies, see the appendix again. Obviously, if the type 2 partially collusive output is not optimal, that is, if $\gamma_{1} \leq \Gamma_{1}$ and/or $\frac{K}{A}$ falls outside the specified interval, the ordering as defined in Proposition 4 applies.

A continuation of the example from the previous section illuminates the results obtained for imperfect antitrust. First, consider the situation where the different types of industries occur with equal probability: $\gamma_{1}=\gamma_{2}=\gamma_{3}=\frac{1}{3}$. It then follows directly that type 2 partial collusion can never be optimal. Note that $\alpha^{* *}=\frac{1}{4}$. Therefore, separate $\alpha \leq \frac{1}{4}$ and $\alpha>\frac{1}{4}$. Then, the following borders apply.

$$
\begin{aligned}
& \Psi_{a}^{\alpha} \equiv\left\{\begin{array}{c}
\frac{1}{4}(1-\alpha) \text { for } \alpha \leq \frac{1}{4} \\
\frac{1}{3}(1-\alpha)^{2} \text { for } \alpha>\frac{1}{4}
\end{array}\right. \\
& \Psi_{b}^{\alpha} \equiv\left\{\begin{array}{c}
\frac{2}{5}(1-\alpha) \text { for } \alpha \leq \frac{1}{4} \\
\frac{1}{3 \alpha}(1-\alpha)^{2} \text { for } \alpha>\frac{1}{4} \quad \text { and }
\end{array}\right. \\
& \Psi_{c}^{\alpha} \equiv 1-\alpha .
\end{aligned}
$$




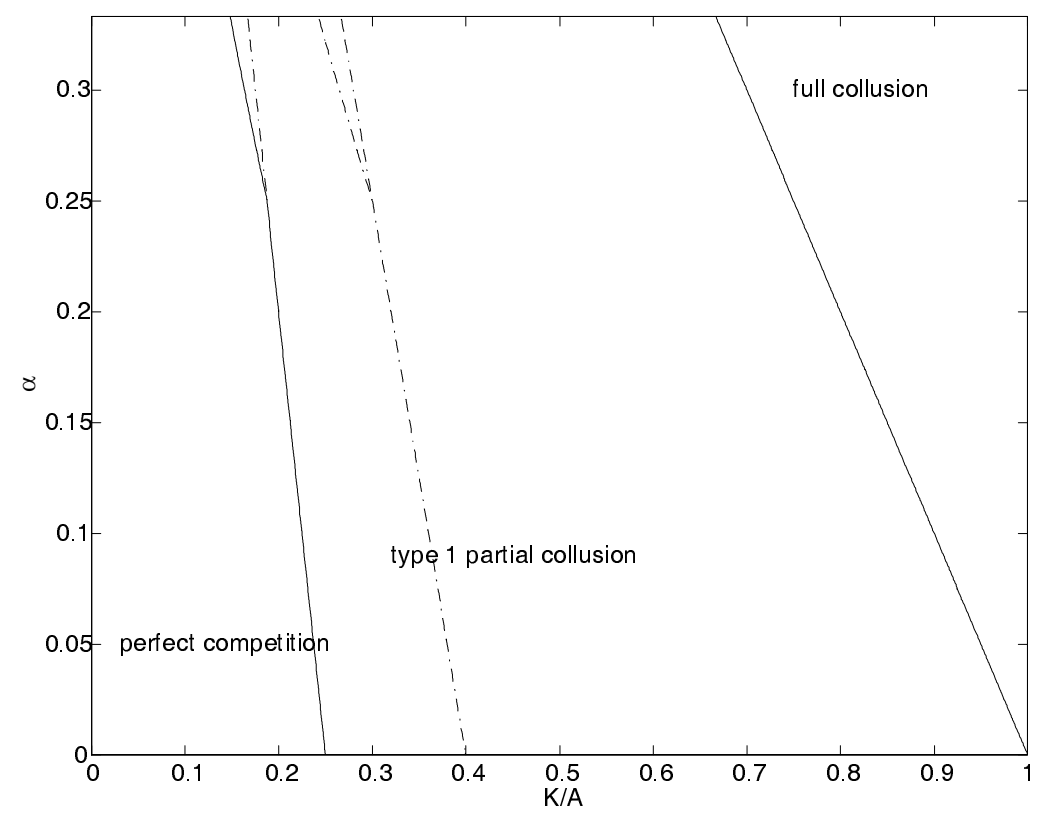

Figure 2: Different optimal antitrust regimes for $\gamma_{1}=\gamma_{2}=\gamma_{3}=\frac{1}{3}$.

Figure 2, in which $\frac{K}{A}$ is set out against $\alpha$, illustrates.

For values of $\alpha$ smaller than $\frac{1}{4}$, the straight lines separate the perfect competition, type 1 partial collusion and the full collusion cases. Obviously, the horizontal axis, where $\alpha=0$, displays the regimes for the original example in Section 3, where antitrust is perfect. When $\alpha$ increases, the perfect competition and partial collusion regions are enlarged linearly, at the expense of the area in which perfect competition is optimal. This is the expected-fines effect of imperfect antitrust. When $\alpha>\frac{1}{4}$, the straight line $\Psi_{a}^{\alpha}$ curves off to the left, thus reducing the region in which perfect competition is optimal, and type 1 partial collusion is best enforced, more than proportionally from the region delineated by the straight continuation of the $\Psi_{a}^{\alpha}$ line-indicated as a dotted line. For these values, the precautionary-collusion consequence of imperfect antitrust take effect.

Next, an example where type 2 partial collusion is both implementable and optimal. Take $A=5000$, implying $\alpha^{*}=\frac{4}{25}$. Then, for $\alpha>\alpha^{*}$ an interval of $\frac{K}{A}$ values for which $\left(q_{1}, q_{3}, q_{3}\right)$ is optimal exists when $\gamma_{1} \geq \frac{2}{3}$ and $\gamma_{2} \leq \gamma_{1}-\frac{1}{2}$. Consider the case $\gamma_{1}=\frac{3}{4}$ and $\gamma_{2}=\gamma_{3}=\frac{1}{8}$. There then appears a transition boundary from perfect competition to full collusion for values of $\alpha$ below $\alpha^{*}=\frac{4}{25}$. For high enough values $\alpha>\frac{4}{25}$, type 2 partial collusion can be implemented and a region in which type 2 partial collusion is preferred is found, as illustrated in Figure 3.

Finally, an example where all four regimes can be optimal. This happens, for example, for $\gamma_{1}=\frac{3}{4}, \gamma_{2}=\frac{3}{16}$ and $\gamma_{3}=\frac{1}{16}$. The different regimes are shown in Figure 4. Note that type 2 partial collusion can again only be implemented for $\alpha>\frac{4}{25}$. 


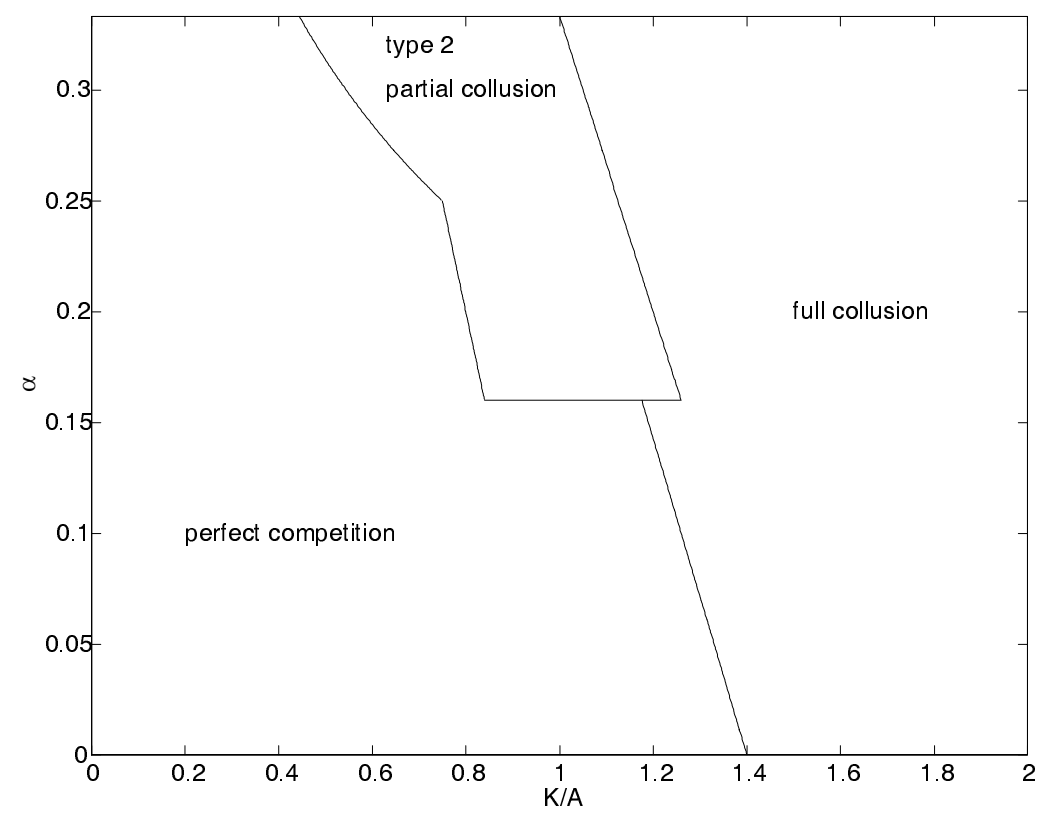

Figure 3: Different optimal antitrust regimes for $\gamma_{1}=\frac{3}{4}, \gamma_{2}=\gamma_{3}=\frac{1}{8}$ and $A=5000$.

In all three of these examples, the qualitative effect of errors in enforcement are apparent. When, in Figure 2, perfect competition is the authority's objective, with a solid enforcement costs of twenty percent of fines $\left(\frac{K}{A}=0.2\right)$, this is a fine policy, as long as the enforcement error remains low. When $\alpha$ comes close to twenty percent, however, the optimal regime no longer is that of perfect competition, but of partial collusion of type 1. Likewise, in Figure 2, when investigation costs are, for example, twenty percent over the level of fines, so that $\frac{K}{A}=1.2$, depending on the error level the optimal enforcement regime may well pass from perfect competition as the standard, to type 2 partial collusion for errors above $\frac{4}{25}$, and even full collusion (or type 1 partial collusion in Figure 4) when $\alpha$ is a little over 0.2 .

\section{Concluding Remarks}

When antitrust authorities are fallible - and aren't we all? - it is shown that the incidence of anticompetitive behavior increases in the enforcement error. That is, competition policy may be counter-productive in that its enforcement stimulates, by the authority's imperfect way of policing, the very behavior it was designed to prevent. Furthermore, it is established that the main original message of Besanko and Spulber (1989), that modest levels of partial collusion are better tolerated than fought, even when antitrust authorities are able to perfectly monitor market behavior and are not budget-contrained, is fortified in case the antitrust enforcement is imperfect. This 


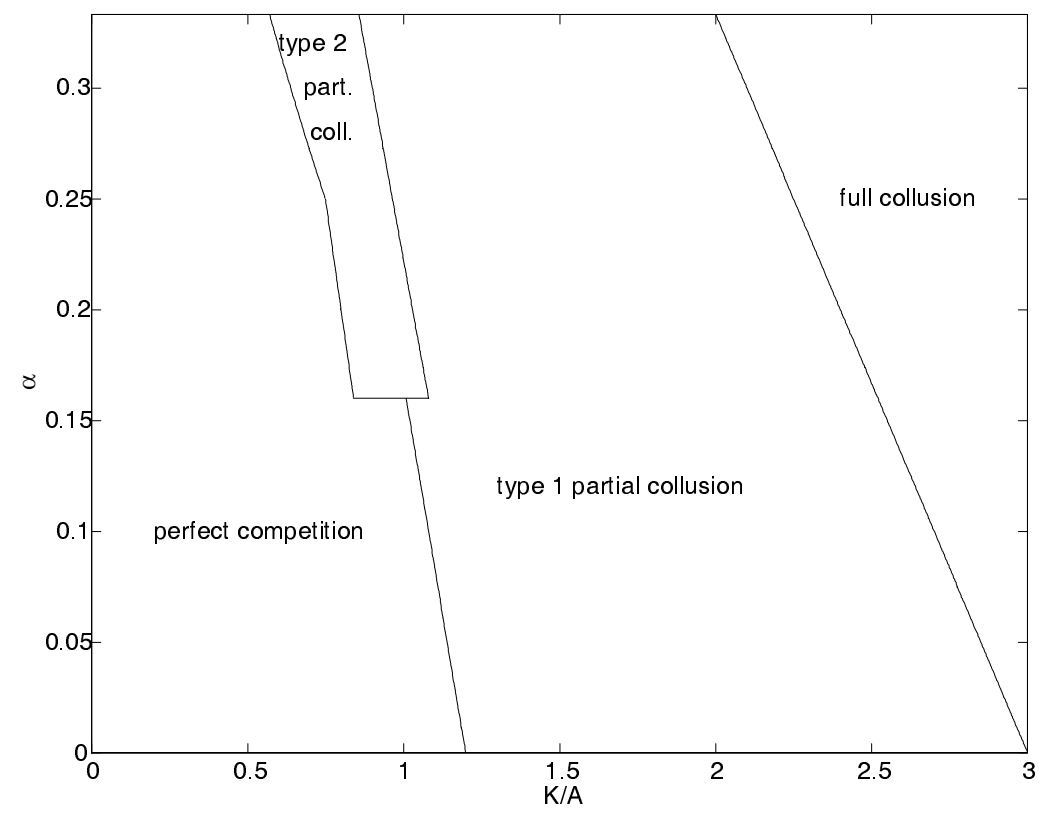

Figure 4: Different optimal antitrust regimes for $\gamma_{1}=\frac{3}{4}, \gamma_{2}=\frac{3}{16}, \gamma_{3}=\frac{1}{16}$ and $A=5000$.

means that antitrust, where it is applied, is to be enforced with great care. ${ }^{19}$

In this respect, some remarks may be worth making. In the realm of the European unification process, (prospective) member states have either adapted if they had some, or adopted where none previously existed, competition policy regimes that tailor to EU example. German competition policy, fairly operational since World War II, had little difficulty connecting with the EU mater. Examples of countries seeking accession to the European Union, such as Romania and Estonia, however, with no former competition discipline, have in very quick pace designed complete regulations, and often quite enormous enforcement offices. It seems not overly sceptical to suspect that these rapid conversions in order to comply with EU law, and be evaluated positively for accession to the union, did not deliver flawless enforcement regimes over-night. ${ }^{20}$

Dutch antitrust is in this context quite an interesting case in point. The Netherlands have, for many years, stood out in working with a so-called "abuse legislation," whereas in the rest of Europe anticompetitive behavior was prohibited by Articles 81

19 Note that this message is importantly different from that delivered by affirmative answers to the question whether no competition policy may be better than some competition policy-cf. Mattoo (2001). In the model developed here, no competition policy would clearly lead to full collusive behavior at all cost levels - albeit due to the fact that no cartel stability argument is offered. What is made here is the simple demand to base competition policy in sound economic analysis.

20 Cf. Schinkel and Thielert (2002) on competition law and practice in Estonia. 
(former 85) and 82 (former 86) of the Treaty of Rome. Only in January 1998 did the Dutch install a new competition law, together with a new enforcement body, the "Nederlandse Mededingingsautoriteit" (NMa). The NMa has since gained a reputation for being tough - yet, not infallible. Clearly, coming from a situation with a lax attitude towards anticompetitive behavior - to the extent that Dutch government facilitated market division and price agreement meetings - to show the new regime has teeth has its value. Nevertheless, novice antitrust institutions are warned not to overshoot the mark, triggering the effects addressed in this paper.

Despite the fact that US enforcement has been shown to be open to trends and fluctuations, there is reason to believe US antitrust is better directed and less likely to err than EU enforcement - relating the present analysis to the current debate on a possible convergence between the two. ${ }^{21}$ The reason for this is that US enforcement is based in case law and jurisprudence to interpret whether or not individual allegations classify as monopolization, whereas Community law is more explicitly delineated and, therefore, more rigid. As a result, US enforcement is more investigatory, with ample opportunity for appeal and debate, than the EU practice, the more regulatory nature of which provides less room for rule of reason argumentation. Although this certainly makes the US enforcement system more expensive, it has the potential benefit of increasing the probability of reaching a just decision. ${ }^{22}$

US critics of competition policy, such as Robert Bork, have argued against the degree of interpretative freedom left to courts in the US system. They hold it leads to unsound and inconsistent decisions, requiring lawyers to decide on what are essentially economic issues. ${ }^{23}$ However, the well-functioning system of academic economics expert witnesses invited to advise parties in antitrust, and testify to judges and juries, shows that any deficiencies on the side of laymen and legal experts are readily repaired. Although the US enforcement system is likely to be more expensive as a result, the present analysis points to possible benefits. The closed EU system is lagging behind in this respect - and signs of catching up should be welcomed for reasons related to our findings.

A number of extensions of the model present themselves. Directly related to the US vs. EU debate is the need to endogenize the probability of error $\alpha$. Introducing variable investigation costs would allow for the probability of error to depend on the level of investigation, $K$. Higher investigation costs in the present model discourage enforcement of antitrust law in partial collusion cases - and in full when very high. If $\alpha$ decreases in $K$, however, possibly leading to perfect antitrust when $K$ is sufficiently high, the model here reduces in the limit to the Besanko-Spulber model with perfect antitrust. This allows for a true cost-benefit analysis of costly, yet less fallible, liti-

\footnotetext{
21 Cf. Ghosal and Gallo (2001) and Lin et.al. (2000) for trends in US DOJ enforcement. See Hildenbrand (2002) for insight into prospective developments of European antitrust.

22 See Martin (1994) for a very extensive comparison of US and EU competition law and practice, and Hildebrand (2002) for a critical review of the role of economic analysis in the latter.

23 Cf. Bork (1993), Chapter 3.
} 
gation procedures. To further relate that model to the present one, it seems worth pursuing to introduce a continuous choice of production levels for the industries, combined with continuous error distributions. Both these extensions would facilitate the essentially empirical question what combination of error and costs is had, and what optimal antitrust enforcement goes with it.

When the allocation of resources and care to cases is subject of choice for the antitrust authority, its performance on the task to maximizing welfare is likely to be better understood when constrained by a budget. An extension of the present model in this direction could provide insight into questions such as whether it is better to allocate resources to a few big cases that are done well and with low enforcement errors, or rather to many cases handled with less care, and hence involving higher values of $\alpha$.

Finally, the present model offers an argument in the discussion on alternative fine structures in antitrust cases. Typically, fines - when given at all - are based on sales. That is, they have the characteristic of $A$ used in the present analysis that they are not directly related to the returns of found anticompetitive behavior. The precautionary collusion effect identified here, derives from the fact that industries run the risk of being fined even when behaving perfectly competitively. Since profits under perfect competition are zero, such wrongfully levied fines based on sales result in an expected loss. This is what tempts firms to collude. Should fines be based on profits, rather than sales, the effect goes at least partly away. Obviously, if monopoly profits can be monitored perfectly, antitrust enforcement need no longer be imperfect, taking the sting out of our model. However, monopoly profits are notoriously hard to measure, so that for example 'window-dressing' arguments can easily support our preprosition that antitrust is fallible. ${ }^{24}$ In that, there is reason to believe that it may be better to fine imperfectly on the basis of imperfect information on profits than doing so using perfect information on sales. This too is subject of further research.

\section{Appendix}

Proof of Proposition 1. It is first shown how the three market structures in the proposition can be implemented most efficiently and the corresponding welfare levels determined. Then it is shown that the other three market structures can either not be implemented, or never be optimal.

1. The perfectly competitive output $\left(q_{1}, q_{2}, q_{3}\right)$ can be implemented by the following policy,

$$
\beta_{2}=\frac{\pi\left(q_{2}, \theta_{1}\right)}{A} \text { and } \beta_{3}=\frac{\pi\left(q_{3}, \theta_{1}\right)}{A} .
$$

This deters type 1 industries from colluding. Note that this value of $\beta_{3}$ also deters type 2 industries from colluding since $\pi\left(q_{3}, \theta_{1}\right)>\pi\left(q_{3}, \theta_{2}\right)$. Substituting the policy

24 Cf. Fisher and McGowan (1983) and the large literature it spawned. 
into welfare function (1) gives

$$
\begin{aligned}
W\left(q_{1}, q_{2}, q_{3}\right)= & \gamma_{1}\left[V\left(q_{1}\right)-\theta_{1} q_{1}\right]+\gamma_{2}\left[V\left(q_{2}\right)-\theta_{2} q_{2}-\frac{K}{A} \pi\left(q_{2}, \theta_{1}\right)\right] \\
& +\gamma_{3}\left[V\left(q_{3}\right)-\theta_{3} q_{3}-\frac{K}{A} \pi\left(q_{3}, \theta_{1}\right)\right] .
\end{aligned}
$$

2. The type 1 partial collusion output $\left(q_{2}, q_{2}, q_{3}\right)$ can be implemented by setting

$$
\beta_{2}=0 \text { and } \beta_{3}=\frac{\pi\left(q_{3}, \theta_{2}\right)}{A} \text {. }
$$

Type 2 industries are deterred from producing $q_{3}$ and type 1 industries are allowed to produce their most preferred output level. Corresponding welfare is

$$
\begin{aligned}
W\left(q_{2}, q_{2}, q_{3}\right)= & \gamma_{1}\left[V\left(q_{2}\right)-\theta_{1} q_{2}\right]+\gamma_{2}\left[V\left(q_{2}\right)-\theta_{2} q_{2}\right] \\
& +\gamma_{3}\left[V\left(q_{3}\right)-\theta_{3} q_{3}-\frac{K}{A} \pi\left(q_{3}, \theta_{2}\right)\right] .
\end{aligned}
$$

3. The full collusion output $\left(q_{2}, q_{3}, q_{3}\right)$ is most efficiently implemented by never investigating, that is, $\beta_{2}=\beta_{3}=0$. Welfare follows as

$$
W\left(q_{2}, q_{3}, q_{3}\right)=\gamma_{1}\left[V\left(q_{2}\right)-\theta_{1} q_{2}\right]+\gamma_{2}\left[V\left(q_{3}\right)-\theta_{2} q_{3}\right]+\gamma_{3}\left[V\left(q_{3}\right)-\theta_{3} q_{3}\right] .
$$

Next, it is established that the remaining three production vectors will never be chosen by the antitrust authority. First consider the type 2 partial collusive output $\left(q_{1}, q_{3}, q_{3}\right)$. It is easily seen that this output can never be implemented, since deterring type 1 industries from producing $q_{3}$-by setting $\beta_{3} \geq \frac{\pi\left(q_{3}, \theta_{1}\right)}{A}$ - will also deter type 2 industries to produce $q_{3}$, as $\pi\left(q_{3}, \theta_{1}\right)>\pi\left(q_{3}, \theta_{2}\right)$. The two remaining outputs have type 1 industries produce $q_{3}$. Although these production levels can be implemented, they can never be welfare maximizing, as follows. Consider $\left(q_{3}, q_{2}, q_{3}\right)$ first. It is easily checked that the most efficient implementation of this output is

$$
\beta_{2}=\frac{\pi\left(q_{2}, \theta_{1}\right)-\pi\left(q_{3}, \theta_{1}\right)+\pi\left(q_{3}, \theta_{2}\right)}{A} \text { and } \beta_{3}=\frac{\pi\left(q_{3}, \theta_{2}\right)}{A} .
$$

The corresponding welfare level is given as

$$
\begin{aligned}
W\left(q_{3}, q_{2}, q_{3}\right)= & \gamma_{1}\left(V\left(q_{3}\right)-\theta_{1} q_{3}-\frac{K}{A} \pi\left(q_{3}, \theta_{2}\right)\right) \\
& +\gamma_{2}\left(V\left(q_{2}\right)-\theta_{2} q_{2}-\frac{K}{A}\left(\pi\left(q_{2}, \theta_{1}\right)-\pi\left(q_{3}, \theta_{1}\right)+\pi\left(q_{3}, \theta_{2}\right)\right)\right) \\
& +\gamma_{3}\left(V\left(q_{3}\right)-\theta_{3} q_{3}-\frac{K}{A} \pi\left(q_{3}, \theta_{2}\right)\right) .
\end{aligned}
$$

It is immediate that $W\left(q_{3}, q_{2}, q_{3}\right)<W\left(q_{2}, q_{2}, q_{3}\right)$, eliminating the output $\left(q_{3}, q_{2}, q_{3}\right)$ as optimal. Finally, consider the 'over-collusive' output $\left(q_{3}, q_{3}, q_{3}\right)$. This can never be optimal, 
since the cost free policy $\beta_{2}=\beta_{3}=0$ will lead to the output $\left(q_{2}, q_{3}, q_{3}\right)$, which generates a higher welfare level than $\left(q_{3}, q_{3}, q_{3}\right)$, even if the latter outcome could be implemented costlessly - which it cannot.

Proof of Proposition 2. Let $\Psi_{a}$ be defined as $\frac{K}{A} \leq \Psi_{a} \Leftrightarrow W\left(q_{1}, q_{2}, q_{3}\right) \geq$ $W\left(q_{2}, q_{2}, q_{3}\right)$. Analogously, let $\Psi_{b}$ be defined by $\frac{K}{A} \leq \Psi_{b} \Leftrightarrow W\left(q_{1}, q_{2}, q_{3}\right) \geq W\left(q_{2}, q_{3}, q_{3}\right)$ and let $\Psi_{c}$ be defined by $\frac{K}{A} \leq \Psi_{c} \Leftrightarrow W\left(q_{2}, q_{2}, q_{3}\right) \geq W\left(q_{2}, q_{3}, q_{3}\right)$. From Proposition (1) it follows that:

$$
\begin{aligned}
\Psi_{a} & =\frac{\gamma_{1}\left(\left[V\left(q_{1}\right)-\theta_{1} q_{1}\right]-\left[V\left(q_{2}\right)-\theta_{1} q_{2}\right]\right)}{\gamma_{2} \pi\left(q_{2}, \theta_{1}\right)+\gamma_{3}\left[\pi\left(q_{3}, \theta_{1}\right)-\pi\left(q_{3}, \theta_{2}\right)\right]}, \\
\Psi_{b} & =\frac{\gamma_{1}\left(\left[V\left(q_{1}\right)-\theta_{1} q_{1}\right]-\left[V\left(q_{2}\right)-\theta_{1} q_{2}\right]\right)+\gamma_{2}\left(\left[V\left(q_{2}\right)-\theta_{2} q_{2}\right]-\left[V\left(q_{3}\right)-\theta_{2} q_{3}\right]\right)}{\gamma_{2} \pi\left(q_{2}, \theta_{1}\right)+\gamma_{3} \pi\left(q_{3}, \theta_{1}\right)}, \\
\Psi_{c} & =\frac{\gamma_{2}\left(\left[V\left(q_{2}\right)-\theta_{2} q_{2}\right]-\left[V\left(q_{3}\right)-\theta_{2} q_{3}\right]\right)}{\gamma_{3} \pi\left(q_{3}, \theta_{2}\right)} .
\end{aligned}
$$

Quite tedious, but fairly straightforward algebra allows for checking that the only possible orderings of these three numbers are the two considered in the proposition.

Proof of Proposition 3. First it is shown how the four outputs in the proposition can be most efficiently implemented and the corresponding welfare levels determined. Then it will be shown that the other two possible outputs can never be optimal.

1. The perfectly competitive output $\left(q_{1}, q_{2}, q_{3}\right)$ can be implemented by setting

$$
\beta_{2}=\frac{\pi\left(q_{2}, \theta_{1}\right)}{(1-\alpha) A} \text { and } \beta_{3}=\max \left\{\frac{\pi\left(q_{3}, \theta_{1}\right)}{(1-\alpha) A}, \frac{\pi\left(q_{3}, \theta_{2}\right)+\frac{\alpha}{1-\alpha} \pi\left(q_{2}, \theta_{1}\right)}{(1-\alpha) A}\right\} .
$$

Welfare follows as $W\left(q_{1}, q_{2}, q_{3}\right)=$

$$
\begin{aligned}
& \gamma_{1}\left[V\left(q_{1}\right)-\theta_{1} q_{1}\right]+\gamma_{2}\left[V\left(q_{2}\right)-\theta_{2} q_{2}-\frac{1}{1-\alpha} \frac{K}{A} \pi\left(q_{2}, \theta_{1}\right)\right]+\gamma_{3} \\
& \times\left[V\left(q_{3}\right)-\theta_{3} q_{3}-\frac{1}{1-\alpha} \frac{K}{A} \max \left\{\pi\left(q_{3}, \theta_{1}\right), \pi\left(q_{3}, \theta_{2}\right)+\frac{\alpha}{1-\alpha} \pi\left(q_{2}, \theta_{1}\right)\right\}\right] .
\end{aligned}
$$

2. The output $\left(q_{2}, q_{2}, q_{3}\right)$ can be implemented by taking $\beta_{2}=0$ and $\beta_{3}=\frac{\pi\left(q_{3}, \theta_{2}\right)}{(1-\alpha) A}$. Welfare is

$$
\begin{aligned}
W\left(q_{2}, q_{2}, q_{3}\right)= & \gamma_{1}\left[V\left(q_{2}\right)-\theta_{1} q_{2}\right]+\gamma_{2}\left[V\left(q_{2}\right)-\theta_{2} q_{2}\right] \\
& +\gamma_{3}\left[V\left(q_{3}\right)-\theta_{3} q_{3}-\frac{1}{1-\alpha} \frac{K}{A} \pi\left(q_{3}, \theta_{2}\right)\right] .
\end{aligned}
$$


3. The (new) output $\left(q_{1}, q_{3}, q_{3}\right)$ requires

$$
\beta_{2} \geq \frac{\pi\left(q_{2}, \theta_{1}\right)}{(1-\alpha) A} \text { and } \beta_{3}=\frac{\pi\left(q_{3}, \theta_{1}\right)}{(1-\alpha) A},
$$

to deter type 1 industries from colluding. Furthermore, in order to allow type 2 industries to collude and given $\beta_{3}$, one needs

$$
\beta_{2} \geq \frac{\pi\left(q_{3}, \theta_{1}\right)-\pi\left(q_{3}, \theta_{2}\right)}{\alpha A} .
$$

Clearly, $\beta_{2}$ should be smaller than or equal to 1 , which requires $\alpha \geq \alpha^{*}$. The final implementation now is

$$
\beta_{2}=\max \left\{\frac{\pi\left(q_{2}, \theta_{1}\right)}{(1-\alpha) A}, \frac{\pi\left(q_{3}, \theta_{1}\right)-\pi\left(q_{3}, \theta_{2}\right)}{\alpha A}\right\},
$$

with corresponding welfare level

$$
\begin{aligned}
W\left(q_{1}, q_{3}, q_{3}\right)= & \gamma_{1}\left[V\left(q_{1}\right)-\theta_{1} q_{1}\right]+\gamma_{2}\left[V\left(q_{3}\right)-\theta_{2} q_{3}-\frac{1}{1-\alpha} \frac{K}{A} \pi\left(q_{3}, \theta_{1}\right)\right] \\
& +\gamma_{3}\left[V\left(q_{3}\right)-\theta_{3} q_{3}-\frac{1}{1-\alpha} \frac{K}{A} \pi\left(q_{3}, \theta_{1}\right)\right] .
\end{aligned}
$$

4. The policy $\beta_{2}=\beta_{3}=0$ implements the fully collusive output and welfare

$$
W\left(q_{2}, q_{3}, q_{3}\right)=\gamma_{1}\left[V\left(q_{2}\right)-\theta_{1} q_{2}\right]+\gamma_{2}\left[V\left(q_{3}\right)-\theta_{2} q_{3}\right]+\gamma_{3}\left[V\left(q_{3}\right)-\theta_{3} q_{3}\right]
$$

is attained.

Finally, it is shown that the remaining outputs $\left(q_{3}, q_{2}, q_{3}\right)$ and $\left(q_{3}, q_{3}, q_{3}\right)$ can never be optimal. It is easily seen that the most efficient way to implement $\left(q_{3}, q_{2}, q_{3}\right)$ is by

$$
\beta_{2}=\frac{\pi\left(q_{2}, \theta_{1}\right)-\pi\left(q_{3}, \theta_{1}\right)+\pi\left(q_{3}, \theta_{2}\right)}{(1-\alpha) A} \text { and } \beta_{3}=\frac{\pi\left(q_{3}, \theta_{2}\right)}{(1-\alpha) A}
$$

resulting in a welfare level of $W\left(q_{3}, q_{2}, q_{3}\right)=$

$$
\begin{gathered}
\gamma_{1}\left[V\left(q_{3}\right)-\theta_{1} q_{3}-\frac{1}{1-\alpha} \frac{K}{A} \pi\left(q_{3}, \theta_{2}\right)\right] \\
+\gamma_{2}\left[V\left(q_{2}\right)-\theta_{2} q_{2}-\frac{1}{1-\alpha} \frac{K}{A}\left(\pi\left(q_{2}, \theta_{1}\right)-\pi\left(q_{3}, \theta_{1}\right)+\pi\left(q_{3}, \theta_{2}\right)\right)\right] \\
+\gamma_{3}\left[V\left(q_{3}\right)-\theta_{3} q_{3}-\frac{1}{1-\alpha} \frac{K}{A} \pi\left(q_{3}, \theta_{2}\right)\right]<W\left(q_{2}, q_{2}, q_{3}\right) .
\end{gathered}
$$

That $\left(q_{3}, q_{3}, q_{3}\right)$ cannot be optimal is immediate from noting that the policy $\beta_{2}=\beta_{3}=0$ returns the fully collusive output with higher welfare. 
Proof of Proposition 4. Define a set of bounds $\Psi_{a}^{\alpha}, \Psi_{b}^{\alpha}, \Psi_{c}^{\alpha}, \Psi_{d}^{\alpha}, \Psi_{e}^{\alpha}$, and $\Psi_{f}^{\alpha}$ as follows.

$$
\begin{aligned}
& W\left(q_{1}, q_{2}, q_{3}\right) \geq W\left(q_{2}, q_{2}, q_{3}\right) \Leftrightarrow \frac{K}{A} \leq \Psi_{a}^{\alpha}= \begin{cases}\Psi_{a}^{\alpha} & \alpha \leq \alpha^{* *} \\
\bar{\Psi}_{a}^{\alpha} & \alpha>\alpha^{* *}\end{cases} \\
& W\left(q_{1}, q_{2}, q_{3}\right) \geq W\left(q_{2}, q_{3}, q_{3}\right) \Leftrightarrow \frac{K}{A} \leq \Psi_{b}^{\alpha}=\left\{\begin{array}{ll}
\underline{\Psi}_{b}^{\alpha} & \alpha \leq \alpha^{* *} \\
\bar{\Psi}_{b}^{\alpha} & \alpha>\alpha^{* *}
\end{array} ;\right. \\
& W\left(q_{2}, q_{2}, q_{3}\right) \geq W\left(q_{2}, q_{3}, q_{3}\right) \Leftrightarrow \frac{K}{A} \leq \Psi_{c}^{\alpha} ; \\
& W\left(q_{1}, q_{2}, q_{3}\right) \geq W\left(q_{1}, q_{3}, q_{3}\right) \Leftrightarrow \frac{K}{A} \leq \Psi_{d}^{\alpha}=\left\{\begin{array}{ll}
\underline{\Psi}_{d}^{\alpha} & \alpha \leq \alpha^{* *} \\
\bar{\Psi}_{d}^{\alpha} & \alpha>\alpha^{* *}
\end{array} ;\right. \\
& W\left(q_{1}, q_{3}, q_{3}\right) \geq W\left(q_{2}, q_{2}, q_{3}\right) \Leftrightarrow \frac{K}{A} \leq \Psi_{e}^{\alpha} ; \text { and } \\
& W\left(q_{1}, q_{3}, q_{3}\right) \geq W\left(q_{2}, q_{3}, q_{3}\right) \Leftrightarrow \frac{K}{A} \leq \Psi_{f}^{\alpha} .
\end{aligned}
$$

Standard algebra delivers

$$
\begin{aligned}
\underline{\Psi}_{a}^{\alpha} & =(1-\alpha) \Psi_{a} ; \\
\bar{\Psi}_{a}^{\alpha} & =(1-\alpha)^{2} \frac{\gamma_{1}\left(\left[V\left(q_{1}\right)-\theta_{1} q_{1}\right]-\left[V\left(q_{2}\right)-\theta_{1} q_{2}\right]\right)}{\left((1-\alpha) \gamma_{2}+\alpha \gamma_{3}\right) \pi\left(q_{2}, \theta_{1}\right)} ; \\
\underline{\Psi}_{b}^{\alpha} & =(1-\alpha) \Psi_{b} ; \\
\bar{\Psi}_{b}^{\alpha} & =(1-\alpha) \frac{\gamma_{1}\left(\left[V\left(q_{1}\right)-\theta_{1} q_{1}\right]-\left[V\left(q_{2}\right)-\theta_{1} q_{2}\right]\right)+\gamma_{2}\left(\left[V\left(q_{2}\right)-\theta_{2} q_{2}\right]-\left[V\left(q_{3}\right)-\theta_{2} q_{3}\right]\right)}{\gamma_{2} \pi\left(q_{2}, \theta_{1}\right)+\gamma_{3}\left(\pi\left(q_{3}, \theta_{2}\right)+\frac{\alpha}{1-\alpha} \pi\left(q_{2}, \theta_{1}\right)\right)} ; \\
\Psi_{c}^{\alpha} & =(1-\alpha) \Psi_{c} ; \\
\underline{\Psi}_{d}^{\alpha} & =(1-\alpha) \frac{V\left(q_{2}\right)-\theta_{2} q_{2}-\left[V\left(q_{3}\right)-\theta_{2} q_{3}\right]}{\pi\left(q_{2}, \theta_{1}\right)-\pi\left(q_{3}, \theta_{1}\right)} ; \\
\bar{\Psi}_{d}^{\alpha} & =(1-\alpha) \frac{\gamma_{2}\left(\left[V\left(q_{2}\right)-\theta_{2} q_{2}\right]-\left[V\left(q_{3}\right)-\theta_{2} q_{3}\right]\right)}{\gamma_{2} \pi\left(q_{2}, \theta_{1}\right)+\gamma_{3}\left(\pi\left(q_{3}, \theta_{2}\right)+\frac{\alpha}{1-\alpha} \pi\left(q_{2}, \theta_{1}\right)\right)-\left(\gamma_{2}+\gamma_{3}\right) \pi\left(q_{3}, \theta_{1}\right)} \\
\Psi_{e}^{\alpha} & =(1-\alpha) \frac{\gamma_{1}\left(\left[V\left(q_{1}\right)-\theta_{1} q_{1}\right]-\left[V\left(q_{2}\right)-\theta_{1} q_{2}\right]\right)-\gamma_{2}\left(\left[V\left(q_{2}\right)-\theta_{2} q_{2}\right]-\left[V\left(q_{3}\right)-\theta_{2} q_{3}\right]\right)}{\gamma_{2} \pi\left(q_{3}, \theta_{1}\right)+\gamma_{3}\left(\pi\left(q_{3}, \theta_{1}\right)-\pi\left(q_{3}, \theta_{2}\right)\right)} \\
\Psi_{f}^{\alpha} & =(1-\alpha) \frac{\gamma_{1}}{1-\gamma_{1}} \frac{\left[V\left(q_{1}\right)-\theta_{1} q_{1}\right]-\left[V\left(q_{2}\right)-\theta_{1} q_{2}\right]}{\pi\left(q_{3}, \theta_{1}\right)} .
\end{aligned}
$$

The result for $\alpha<\alpha^{* *}$ follows straightforwardly. Now consider the case where $\alpha>\alpha^{* *}$. The objective now is to order $\bar{\Psi}_{a}^{\alpha}, \bar{\Psi}_{b}^{\alpha}, \bar{\Psi}_{c}^{\alpha}, \bar{\Psi}_{d}^{\alpha}$. The last number can be skipped by assumption. The only feasible orderings of the other three numbers are (again) $\bar{\Psi}_{a}^{\alpha}<\bar{\Psi}_{b}^{\alpha}<$ $\Psi_{c}^{\alpha}$ and $\bar{\Psi}_{c}^{\alpha}<\bar{\Psi}_{b}^{\alpha}<\bar{\Psi}_{a}^{\alpha}$.

Proof of Proposition 5. For the optimality of $\left(q_{1}, q_{3}, q_{3}\right)$ it is required that $\frac{K}{A}$ is larger than $\Psi_{d}^{\alpha}$ but smaller than $\Psi_{e}^{\alpha}$ and $\Psi_{f}^{\alpha}$. First consider $\alpha<\alpha^{* *}$. In order for an interval of $\frac{K}{A}$ values for which $\left(q_{1}, q_{3}, q_{3}\right)$ to exist, it is needed that $\Psi_{e}^{\alpha} \geq \Psi_{d}^{\alpha}$ and $\Psi_{f}^{\alpha} \geq \Psi_{d}^{\alpha}$. 
For $\alpha \leq \alpha^{* *}$ these inequalities reduce to

$$
\begin{aligned}
\gamma_{1} & \geq \frac{\gamma_{2}\left(\pi\left(q_{2}, \theta_{1}\right)+\pi\left(q_{3}, \theta_{2}\right)-\pi\left(q_{3}, \theta_{1}\right)\right)+\left(\pi\left(q_{3}, \theta_{1}\right)-\pi\left(q_{3}, \theta_{2}\right)\right)}{\left(\pi\left(q_{2}, \theta_{1}\right)-\pi\left(q_{3}, \theta_{1}\right)\right) \frac{V\left(q_{1}\right)-\theta_{1} q_{1}-\left[V\left(q_{2}\right)-\theta_{1} q_{2}\right]}{V\left(q_{2}\right)-\theta_{2} q_{2}-\left[V\left(q_{3}\right)-\theta_{2} q_{3}\right.}+\left(\pi\left(q_{3}, \theta_{1}\right)-\pi\left(q_{3}, \theta_{2}\right)\right)}, \\
\frac{\gamma_{1}}{1-\gamma_{1}} & \geq \frac{\pi\left(q_{3}, \theta_{1}\right)}{\pi\left(q_{2}, \theta_{1}\right)-\pi\left(q_{3}, \theta_{1}\right)} \frac{V\left(q_{2}\right)-\theta_{2} q_{2}-\left[V\left(q_{3}\right)-\theta_{2} q_{3}\right]}{V\left(q_{1}\right)-\theta_{1} q_{1}-\left[V\left(q_{2}\right)-\theta_{1} q_{2}\right]} .
\end{aligned}
$$

Note that there always exist a $\gamma_{1}$ satisfying these inequalities (as can be verified by letting $\gamma_{1}$ approach 1). Now consider $\alpha>\alpha^{* *}$. It is easily verified that $\bar{\Psi}_{d}^{\alpha} \leq \underline{\Psi}_{d}^{\alpha}$ for $\alpha \geq \alpha^{* *}$. Hence the above conditions also suffice for the case $\alpha>\alpha^{* *}$. The interval of $\frac{K}{A}$ values for which $\left(q_{1}, q_{3}, q_{3}\right)$ then is optimal is given by

$$
\left[\Psi_{d}^{\alpha}, \min \left\{\Psi_{e}^{\alpha}, \Psi_{f}^{\alpha}\right\}\right] .
$$

\section{References}

[1] Adams, W. and J.W. Brock, Antitrust Economics on Trial, Princeton University Press, Princeton, 1991;

[2] Andreoni, J., Erard, B., Feinstein, J., "Tax Compliance," Journal of Economic Literature, 34, 1998, 818-869;

[3] Baumol, W.J. and J.A. Ordover, "Use of Antitrust to Subvert Competition," Journal of Law \& Economics, 28, 1985, 247-265;

[4] Becker, G.S., "Crime and Punishment: An Economic Approach," Journal of Political Economy, 76, 1968, 169-217;

[5] Besanko, D. and D.F. Spulber, "Antitrust Enforcement under Asymmetric Information," The Economic Journal, 99, 1989, 408-425;

[6] Bork, R.H., "Legislative Intent and the Policy of the Sherman Act," Journal of Law \& Economics, 9, 1966, 7-48;

[7] Bork, R.H., The Antitrust Paradox: Policy at War with Itself, Basic Books, New York, revised edition, 1993;

[8] Cyrenne, P., "On Antitrust Enforcement and the Deterrence of Collusive Behaviour," Review of Industrial Organization, 14, 1999, 257-272;

[9] Davies, S.W., Drifield, N.L., Clarke, R., "Monopoly in the UK: What Determines Whether the MMC finds Against the Investigated Firm?," Journal of Industrial Economics, 47, 1999, 263-283; 
[10] Demsetz, H., "Two Systems of Belief about Monopoly," in: H. Goldschmid, H.M. Mann and J.F. Weston (eds.), Industrial Concentration: The New Learning, Little, Brown \& Company, Boston, 164-84;

[11] Fisher, F.M. and J.J. McGowan, "On the Misuse of Accounting Rates to Infer Monopoly Profits," American Economic Review, 73(1), 1983, 82-97;

[12] Fisher, F.M., "Diagnozing Monopoly," in J. Monz (ed.), Industrial Organization, Economics, and the Law, MIT Press, Cambridge, MA, 1991;

[13] Gallo, J.C., K. Dau-Schmidt, J.L. Craycraft and C.J. Parker, "Department of Justice Antitrust Enforcement, 1955-1997: An Empirical Study," Review of Industrial Organization, 17, 2000, 75-133;

[14] Ghosal, V. and Gallo, J., "The cyclical behavior of the Department of Justice's antitrust enforcement activity," International Journal of Industrial Organization, 19, 2001, 27-54;

[15] Hildebrand, D., The Role of Economic Analysis in the EC Competition Rules, Kluwer Law International, The Hague, second edition, 2002;

[16] -, "The European School in EC Competition Law," World Competition, 25, 2002, 3-23;

[17] Kaplow, L. and Shavell, S., "Optimal Law Enforcement with Self-Reporting Behavior," Journal of Political Economy, 102, 1996, 553-570;

[18] Lauk, M., "Econometric Analysis of the Decisions of the German Cartel Office," working paper, TU Darmstadt, 2002;

[19] Lin, P., R. Baldev, M. Sandfort, D. Slottje, "The US Antitrust System and Recent Trends in Antitrust Enforcement," Journal of Economic Surveys, 14, 2000, 255-306;

[20] Martin, S., Industrial Economics, Economic Analysis and Public Policy, Prentice Hall, Englewood Cliffs, second edition, 1993;

[21] Mattoo, A., "Can no competition policy be better than some competition policy?," International Journal of Industrial Organization, 19, 2001, 55-77;

[22] Posner, R.A., Antitrust Law, An Economic Perspective, University of Chicago Press, 1st edition, 1976, 2nd edition, 2002;

[23] Reinganum, J.F. and L.L. Wilde, "The Economics of Income Taxation: Compliance in a Principal-Agent Framework," Journal of Public Economics, 26, 1985, $1-18$; 
[24] Schinkel, M.P. and J. Thielert, "Estonia's Competition Policy, A Critical Evaluation towards EU Accession," Meteor Research Memorandum, RM/02/020, Universiteit Maastricht, 2002 (forthcoming in European Competition Law Review);

[25] Scotchmer, S. and Slemrod, J., "Randomness in Tax Enforcement," Journal of Public Economics, 38, 1989, 17-32;

[26] Souam, S., "Optimal antitrust policy under different regimes of fines," International Journal of Industrial Organization, 19, 2001, pp.1-26;

[27] Spulber, D.F., Regulation and Markets, MIT Press, Cambridge, MA, 1989. 